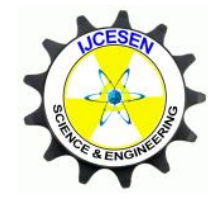

Copyright (C) IJCESEN
International Journal of Computational and

Experimental $\boldsymbol{S}$ cience and Engineering

(IJCESEN)

Vol. 4-No.3 (2018) pp. 20-24

http://dergipark.gov.tr/ijcesen

Research Article

\title{
Numerical Simulation of Casing Stress during Multi-stage Fracturing Based on Stage Finite Element Method
}

\author{
Xueli GUO ${ }^{1 *}$, Jun LI ${ }^{1}$, Gonghui LIU ${ }^{1,2}$, and Hui YAN ${ }^{1}$ \\ ${ }^{1}$ China University of Petroleum, Beijing, The College of Petroleum Engineering, 102249, Beijing-China \\ ${ }^{2}$ Beijing University of Technology, Beijing-China \\ * Corresponding Author : clouder0713@163.com \\ ORCID: 0000-0002-9774-799X
}

\section{Article Info:}

DOI: $10.22399 /$ ijcesen.418035

Received : 24 April 2018

Accepted : 7 August 2018

\section{Keywords :}

Stage finite element method

Casing stress

Fracturing

Cement channelling

Transient temperature

\begin{abstract}
:
During multi-stage hydro-fracturing operation, casing deformation issues have widely occurred in the Weiyuan-Changning National Shale Gas Demonstration Area, which dramatically reduce the productions of shale gas wells. It is important to access the influence of multiple factors on casing during fracturing operations. In this paper, a stage finite element method is presented to establish three-dimensional physical and finite element casing-cement sheath-formation (CCF) models during volume fracturing processes. It considers the influences of initial stress and displacement state at and near the wellbore. Loads from the initial stress field, fracturing pressure, and transient temperature changes are incorporated in the models. Cement channelling, cement elastic modulus, casing eccentricity, and fracturing pump rate are also the variables taken into account. Sensitivity analyses are conducted to reveal which one has the greatest influence on casing stress. The results indicate that casing stress is highly affected by cement channelling. Low casing stress can be guaranteed by high cement sheath modulus and optimal fracturing pressure. Casing transient temperature is significantly reduced by the large pump rate, then a certain thermal stress generating in the casing. Among all the factors, casing eccentricity has a minor influence on casing stress.
\end{abstract}

\section{Introduction}

The characteristics of geological conditions of shale formation are "poor storage environment", "buried deep", "severe fault structure", "heterogeneous production layer" [1]. Horizontal well drilling and multi-stage fracturing are two key techniques for the development of shale gas [2]. During multi-stage fracturing processes, a large amount of fracturing fluids are injected into the borehole in large pump rate and high pressure [3]. High pressure and complex downhole conditions would increase the risk of casing integrity $[4,5]$.

From 2009 to 2016, 101 fracturing wells have been drilled by Petro-China in Weiyuan-Changning National Shale Gas Demonstration Area, including 90 horizontal wells, while 32 wells of which faced with casing deformation failure problems with 47 deformation points, shown in Figure 1. Wells with casing deformation failure account for $31 \%$ [6],
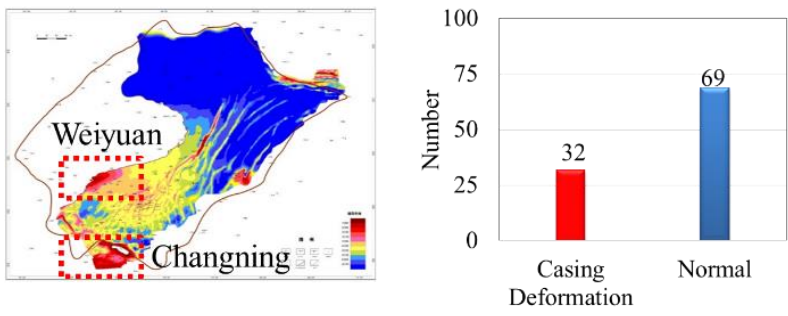

Figure 1. Casing deformation in shale gas play

which shown serious casing deformation failure problems during fracturing of shale gas. Finite element method is an effective way to accurately calculate casing stress in a complex downhole condition. In this paper, three-dimensional physical and finite element models of casing-cement sheathformation (CCF) are established based on the stage finite element method. Cement channelling, cement elastic modulus, casing eccentricity, and fracturing 
pump rate are the variables taken in account to reveal the influences in casing deformation.

\section{Model and Development}

The researchers did not consider the influence of initial geo-stress, they loaded the stress directly after establishing the CCF model [7]. Only a few scholars loaded the stress in the formation before drilling, which is called stage finite element method (FEM) [8].

\subsection{Stage finite element method}

The whole drilling, casing, cementing, and fracturing processes are considered by the stage FEM. Before drilling, the initial stress has already existed in the formation. So it is loaded and the displacement field is zero in the formation. The rock originally occupied borehole volume. When a wellbore is drilled, it is removed, which results in stress concentration around the hole. After drilling, mud exerts some pressure- $P_{\mathrm{i}}$ on the borehole wall, which will reduce the stress concentration around the hole. After setting casing and cementing the annulus, the disturbance to the stress field still exists. During fracturing process, the casing pressure increases dramatically and the casing string is cooled, the stress disturbance around the hole will be amplified, possibly leading to the casing integrity problem. For the conventional method, the initial stresses are directly loaded in the model after drilling.

\subsection{Model establishment}

SLG (Solid Liquid Gas) Map can be obtained from the IBC (Isolation Scanner), shown in Figure 2. Three kinds of colors represented the gas, liquid, and cement sheath, respectively. Casing deformation has occurred in $2579 \mathrm{~m}$ and $2331 \mathrm{~m}$, where the cement channel and casing eccentricity are serious.

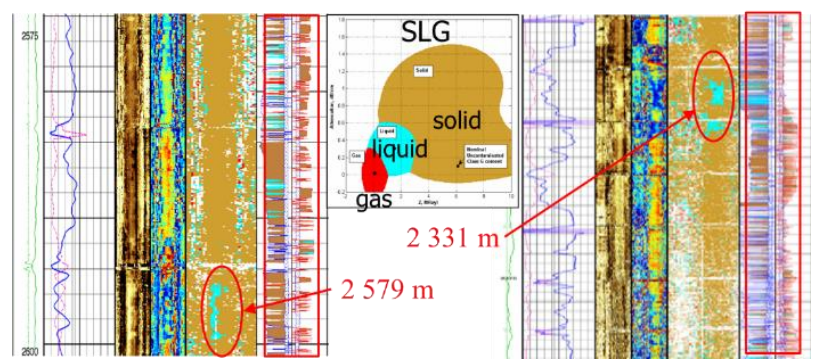

Figure 2. SLG (Solid Liquid Gas) Map from the IBC (Isolation Scanner)

Based on the stage FEM, a three-dimensional physical CCF model is established considering transient thermal-pressure coupling effect, shown in Figure 3. The parameters of cement channelling angle and casing eccentricity are defined as $e$ and $\theta$, respectively. Other factors, like pump rate- $Q$, fracturing pressure- $P_{\mathrm{f}}$, and cement elastic modulus$E_{\mathrm{c}}$ are also taken into account to investigate the influences on casing stress. The stress boundaries are $\sigma_{\mathrm{H}}, \sigma_{\mathrm{h}}, \sigma_{\mathrm{v}}$, which represent the maximum horizontal stress, minimum horizontal stress, and vertical stress, respectively.

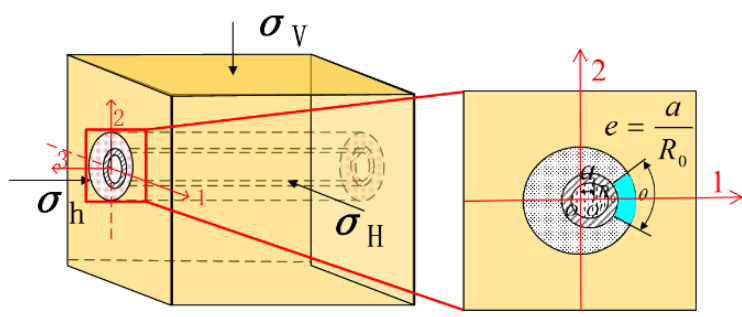

Figure 3. Three-dimentional CCF physical model

The finite element model is analysed using the ABAQUS finite element software to investigate the influence on casing, shown in Figure 4. The geometrical dimensions of the CCF model are shown as following: the wellbore diameter is $215.9 \mathrm{~mm}$, the casing diameter is $139.7 \mathrm{~mm}$, and the casing thickness is $9.17 \mathrm{~mm}$. According to the Saint-Venant principle, the formation boundary dimension should be 5-6 times larger than that of the well-bore geometry. In view of this, the model geometry is $2 \times 2$ $\mathrm{m}$, while the corresponding wellbore diameter and axial length are $0.2159 \mathrm{~m}$ and $2 \mathrm{~m}$, respectively. The stress boundaries are loaded using the key words *Predefined Field.

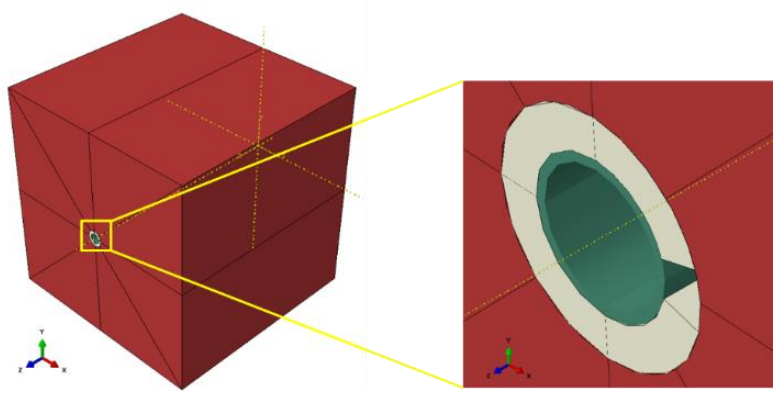

Figure 4. Three-dimentional CCF finite element model

\subsection{Control equations}

The pump rate can influence the convective heat transfer coefficient- $h$. When large amounts of fracturing fluids are injected into the wellbore, they are usually in a turbulent state. The transient heat transfer model is shown in Figure 5. Heat transfer coefficient between the fracturing fluid and the inner casing wall can be calculated using Marshall Model, shown in Eq. (1). [9]

$$
\begin{aligned}
h=0.0107 \frac{k_{m}}{D} L\left\{\rho D_{\text {eff }} \frac{4 Q}{\pi D^{2}} /\left[K\left(\frac{3 n+1}{4 n}\right)^{n}\left(\frac{8 Q}{15 \pi D^{3}}\right)^{n-1}\right]\right\}^{0.67} \\
\\
\left\{K\left(\frac{3 n+1}{4 n}\right)^{n}\left(\frac{8 Q}{15 \pi D^{3}}\right)^{n-1} C_{m} / k_{m}\right]^{0.33}
\end{aligned}
$$

Where $h$ is the heat transfer coefficient, $\mathrm{W} \cdot \mathrm{m}^{-2} \cdot{ }^{\circ} \mathrm{C}^{1}$; $D$ is the pipe diameter in calculation, $\mathrm{m} ; D_{\text {eff }}$ is the equivalent diameter, $\mathrm{m} ; \rho$ is the drilling mud density, 
$\mathrm{kg} \cdot \mathrm{m}^{-3} ; \mu_{w, a p p}$ is the apparent viscosity, $\mathrm{Pa} \cdot \mathrm{s} ; Q$ is the fracturing pump rate, $\mathrm{m}^{3} \cdot \mathrm{min}^{-1} ; C_{m}$ is the fluid specific heat capacity, $\mathrm{J} \cdot \mathrm{kg}^{-1} \cdot{ }^{\circ} \mathrm{C}^{-1} ; n$ is the fluid rheological index, for fracturing fluid $n<1 ; K$ is the fluid consistency coefficient, $\mathrm{Pa} \cdot \mathrm{s}^{-\mathrm{n}}$.

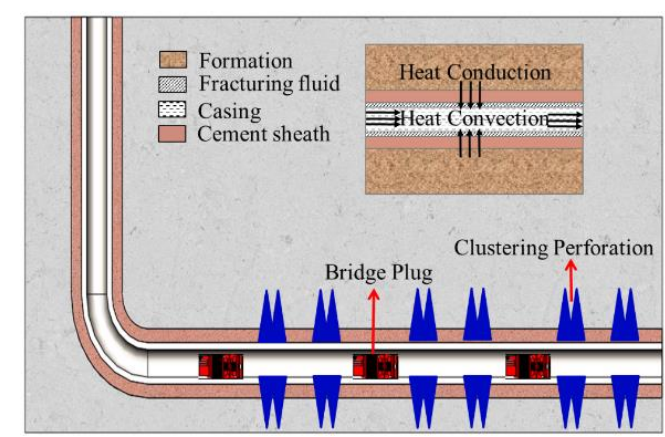

Figure 5. The transient heat transfer process

For the CCF model, the solution of unidimensional time-dependent equation in cylindrical geometry, the heat transfer equation, is obtained as timedependent temperature distribution by $\boldsymbol{E q}$. (2). [1012]

$$
k_{i}\left(\frac{\partial^{2} T^{i}}{\partial z^{2}}+\frac{\partial^{2} T^{i}}{\partial r^{2}}+\frac{1}{r} \frac{\partial T^{i}}{\partial r}\right)+q_{i}=C_{p i} \rho_{i} \frac{\partial T^{i}}{\partial t}
$$

where $k_{\mathrm{i}}$ is the coefficient of thermal conductivity, $\mathrm{W} \cdot \mathrm{m}^{-1} \cdot{ }^{\circ} \mathrm{C}^{1} ; C_{p \mathrm{i}}$ is the specific heat capacity, $\mathrm{J} \cdot \mathrm{kg}^{-1} \cdot{ }^{\circ} \mathrm{C}$ ${ }^{1} ; \rho_{\mathrm{i}}$ is the density, $\mathrm{kg} \cdot \mathrm{m}^{-3} ; q_{\mathrm{i}}$ is The heat source density, $\mathrm{W} \cdot \mathrm{m}^{-3} ; T^{\mathrm{i}}$ is the thermal field, ${ }^{\circ} \mathrm{C} ; \mathrm{i}=1,2,3$, is represented the casing, cement sheath, and formation, respectively; $t$ is the time, $\mathrm{s} ; r$ is the radius of the CCF model, $\mathrm{m}$.

After calculating the thermal field, the stress of CCF under thermal-pressure coupling in cylindrical geometry can be obtained by $\boldsymbol{E} \boldsymbol{q}$. (3).

$$
\varepsilon=\mathbf{D} \boldsymbol{\sigma}
$$

where $\boldsymbol{\varepsilon}$ is the strain array under the condition of thermal-pressure coupling; $\boldsymbol{\sigma}$ is the stress matrix; D is the elastic matrix.

Shale formation contains numerous inherent bedding planes [13], so it can be seen as the transverse isotropy material. D can be written by:

$$
\mathbf{D}=\left[\begin{array}{cccccc}
1 / E_{1} & -\mu_{1} / E_{1} & -\mu_{2} / E_{2} & 0 & 0 & 0 \\
-\mu_{1} / E_{1} & 1 / E_{1} & -\mu_{2} / E_{2} & 0 & 0 & 0 \\
-\mu_{2} / E_{2} & -\mu_{2} / E_{2} & 1 / E_{2} & 0 & 0 & 0 \\
0 & 0 & 0 & G_{2} & 0 & 0 \\
0 & 0 & 0 & 0 & G_{2} & 0 \\
0 & 0 & 0 & 0 & 0 & G_{1}
\end{array}\right]
$$

where $E_{\mathrm{i}}$ is the elastic modulus, $\mathrm{GPa}$; $G_{\mathrm{i}}$ is the shear modulus, $\mathrm{GPa} ; \mu_{\mathrm{i}}$ is the Poisson's ratio; $G_{1}=E_{1} / 2\left(1+\mu_{1}\right) ; \quad G_{2}=E_{1} E_{2} /\left(E_{1}+E_{2}+2 \mu_{2} E_{2}\right) ; \quad \mathrm{i}=1,2$ represent the parameters of parallel and vertical shale bedding.

\subsection{Parameter setting}

The internal casing pressure is obtained from the pump pressure plus the hydrostatic fluid pressure downhole. The external boundary stress is the geostress of shale reservoir. Taken different pump rates, cement channelling angles, casing eccentricities, fracturing pressures, and cement moduli into consideration, the casing stresses are calculated to reveal which factor is the most important for casing deformation.

Unless otherwise mentioned, the applied maximum horizontal stress $\sigma_{\mathrm{H}}$ is $82 \mathrm{MPa}$, the minimum horizontal stress $\sigma_{\mathrm{h}}$ is $55 \mathrm{MPa}$, the vertical stress $\sigma_{\mathrm{v}}$ is $57 \mathrm{MPa}$, the formation temperature $T_{\infty}{ }^{3}$ is $100{ }^{\circ} \mathrm{C}$, and the fluid temperature $T_{a}$ is $20^{\circ} \mathrm{C}$. The thermal and mechanical properties of different materials are presented in Table 1.

Table 1. Thermal and mechanical properties

\begin{tabular}{|c|c|c|c|c|}
\hline Parameters & $\begin{array}{l}\text { Casi } \\
\text { ng }\end{array}$ & $\begin{array}{l}\text { Cem } \\
\text { ent } \\
\text { Shea } \\
\text { th }\end{array}$ & $\begin{array}{l}\text { For } \\
\text { mati } \\
\text { on }\end{array}$ & Fluid \\
\hline $\begin{array}{c}\text { Elastic Modulus } \\
E_{\mathrm{i}} /(\mathrm{GPa})\end{array}$ & 210 & 10 & $\begin{array}{c}22- \\
40\end{array}$ & - \\
\hline Poisson's ratio $\mu_{\mathrm{i}}$ & 0.3 & 0.15 & 0.23 & - \\
\hline $\begin{array}{c}\text { Coefficient of } \\
\text { Thermal } \\
\text { Expansion } \\
\alpha_{\mathrm{i}} /\left(10^{-5} .{ }^{\circ} \mathrm{C}^{-1}\right)\end{array}$ & 1.06 & 1.0 & 1.02 & - \\
\hline $\begin{array}{c}\text { Coefficient of } \\
\text { Thermal } \\
\begin{array}{c}\text { Conductivity } k_{\mathrm{i}} \\
/\left(\mathrm{W} \cdot \mathrm{m}^{-1} \cdot{ }^{\circ} \mathrm{C}^{-1}\right)\end{array}\end{array}$ & 58.2 & 1.74 & 1.0 & 1.73 \\
\hline $\begin{array}{c}\text { Specific Heat } \\
\text { Capacity } \mathrm{C}_{\mathrm{i}} / \\
\left(\mathrm{J} \cdot \mathrm{Kg}^{-1} .^{\circ} \mathrm{C}^{-1}\right)\end{array}$ & 460 & 1830 & 1043 & 4200 \\
\hline $\begin{array}{c}\text { Density } \rho_{\mathrm{i}} / \\
\left(\mathrm{kg} \cdot \mathrm{m}^{-3}\right)\end{array}$ & 7850 & 1800 & 2500 & 1000 \\
\hline
\end{tabular}

\section{Results and Analysis}

\subsection{Transient temperature and stress}

A total of 5 simulations were performed to investigate numerically the transient temperature and stress of casing during fracturing process. Simulations were conducted using ABAQUS program. The pump rates were set as $0 / 1 / 3 / 16$ $\mathrm{m}^{3} / \mathrm{min}$. The results are shown in Figure.7. It is seen that the downhole temperature would drop dramatically in a few minutes when the pump rate is larger than $3 \mathrm{~m}^{3} / \mathrm{min}$, while casing stress increases dramatically. If there is no thermal transferring, temperature will be in the same and the stress will increase linearly. The larger the pump rate, the lower the downhole temperatures and the higher the casing stress. 


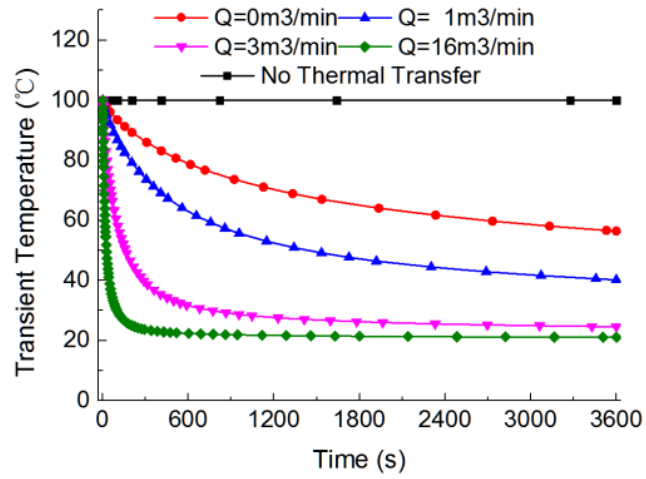

(a)

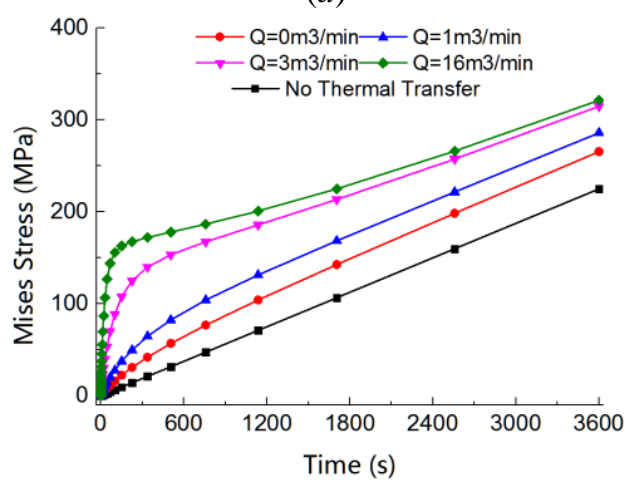

(b)

Figure 6. The Influence of Pump Rate on Casing.

(a) Transient Temperature. (b) Transient Mises Stress.

\subsection{The Influence of Different Factors on Casing Stress}

Using the thermal-pressure coupling model, simulations for different cement channelling- $\theta$, cement sheath elastic moduli- $E$, casing eccentricity$e$, and fracturing pressure- $P_{\mathrm{m}}$ are conducted to investigate the influences on casing stress. The results are shown in Figure 7.

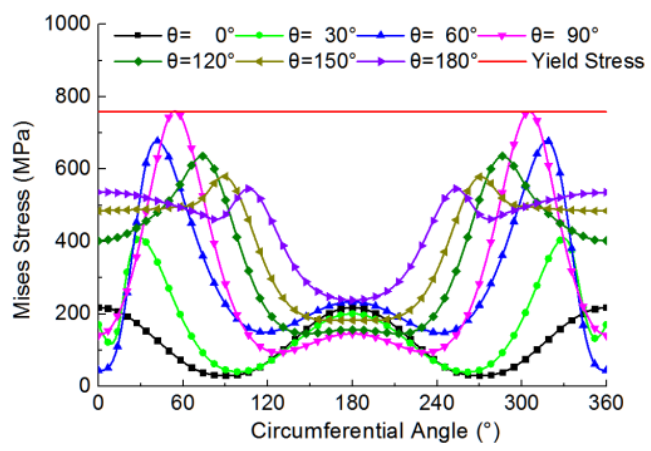

(a)

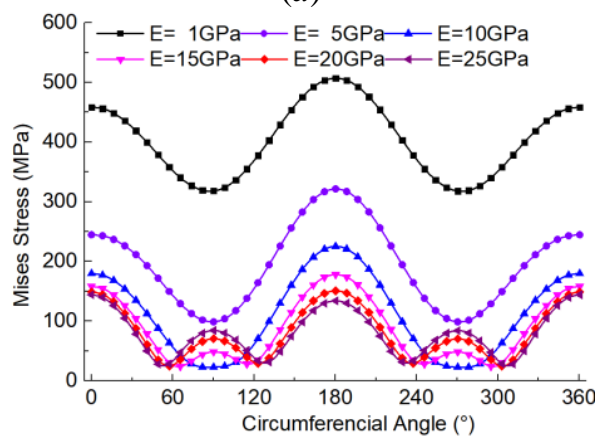

(b)

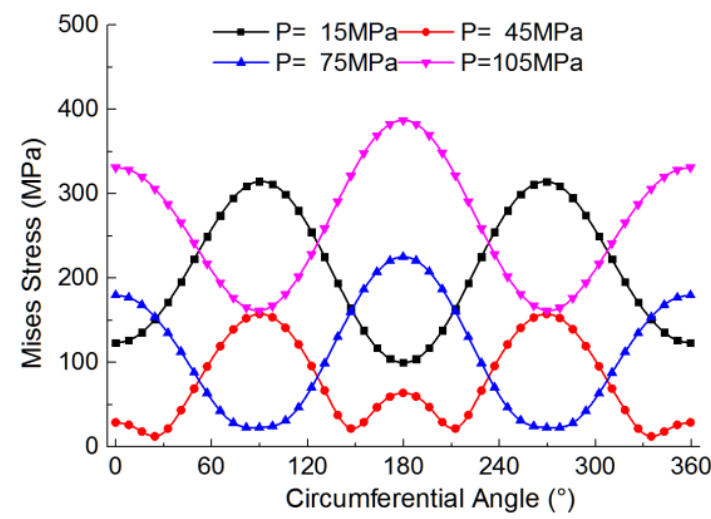

(c)

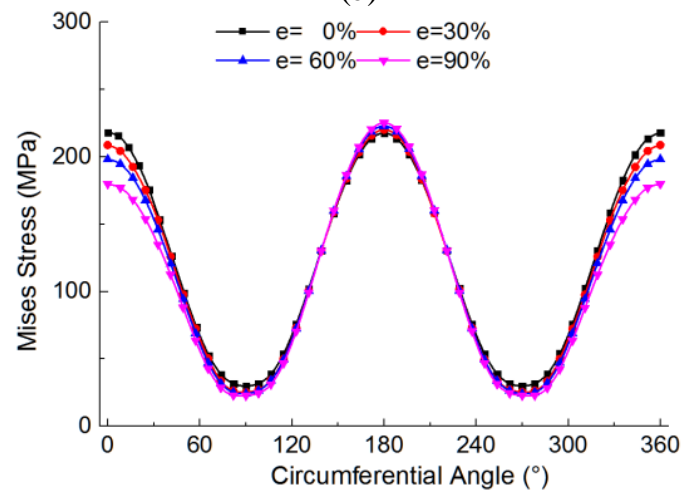

(d)

Figure 7. The Influence of Different Factors on Casing Stress (a) Cement Channelling. (b) Cement Modulus. (c)

Fracturing Pressure. (d) Casing Eccentricity.

Figure 7 (a) shows that the casing stress will increase dramatically with the increasing of $\theta$. For the casing of P110 steel grade, the yield stress is $758 \mathrm{MPa}$, shown as the red line. The largest Von Mises stress of casing $750 \mathrm{MPa}$ appears at the angle of $90^{\circ}$, which is almost close to the yield stress. The risk of casing failure is very high. Figure 7 (b) shows that the lower the cement modulus, the higher the casing stress. When the cement modulus is larger than that of formation-22GPa, the stress could hardly decrease. Figure 7 (c) shows that lower and higher pressure can increase the casing stress. Obviously, suitable pressure can guarantee a low casing stress. Figure 7 (d) shows that no matter how serious casing eccentricity is, casing stress is almost the same. The casing eccentricity has minor influence on casing stress.

\subsection{Comparison of different factors}

The maximum stresses of each factor are presented in Figure 8. It is seen that the cement channel has the greatest influence on casing stress, while the casing eccentricity has the least influence on casing stress. Cement modulus, fracturing pressure, and pump rate have some influences on casing stress. 


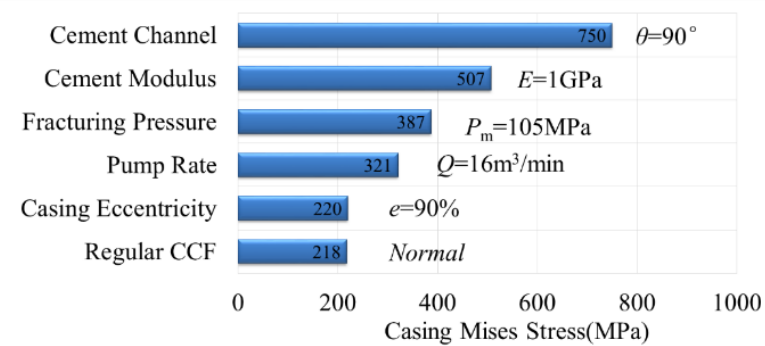

Figure 8. The Maximum of Mises Stress of Different Factors

\section{Conclusions}

Based on stage finite element method, threedimensional transient thermal-pressure CCF models are established. The effects of different factors on casing stress are conducted to reveal which one has the greatest influence on casing stress. Conclusions can be drawn from the former analyses results.

(1) Casing stress can dramatically increase with the increasing of cement channelling. The largest casing Mises stress-750 MPa appears at the channelling angle of $90^{\circ}$, which is almost the same as the yield stress.

(2) Large cement sheath modulus, optimal fracturing pressure can guarantee a lower casing stress.

(3) The transient temperature drops dramatically with the increase of pump rate, leading to a certain thermal stress. Casing eccentricity has a minimum influence on casing stress.

\section{Acknowledgement}

Authors thanks to Dassault Systemes Simulia Corparation for providing ABAQUS software program. This paper was supported by the National Natural Science Foundation, Project No. 51674272, and China Petroleum \& Chemical Corporation, Project No. HX20180001.

This paper was presented in " 4 rd International Conference on Computational and Experimental Science and Engineering (ICCESEN-2017)"

\section{References}

[1] Lv Z., Wang L., Deng S., et al. China Shale Gas Exploration: Early Sichuan Basin Longmaxi Shale Gas Stimulation and Completion Case Study, SPE/IADC Middle East Drilling Technology Conference \& Exhibition. Society of Petroleum Engineers, Dubai 2013, DOI:10.2118/166746-MS.

[2] Sugden C., Johnson J., Chambers M., et al. Special Considerations in the Design Optimization of High Rate, Multistage Fractured Shale Wells, IADC/SPE Drilling Conference and Exhibition. Society of Petroleum Engineers, San Diego ,2012, DOI:10.2118/151470-MS.
[3] Zhou C., Wu X., Li H., et al. Influence of In-situ Stress Distribution on Selection of Fracturing Fluid Backflow Technology, Acta Physica Polonica A, 130(2016) 347-351. DOI: 10.12693/APhysPolA.130.347.

[4] Davies R. J., Almond S., Ward R. S., et al. Oil and gas wells and their integrity: Implications for shale and unconventional resource exploitation, Marine and Petroleum Geology, 56(2014) 239-254. DOI:10.1016/j.marpetgeo.2014.03.001.

[5] Rocha-Valadez T., Mentzer R. A., Hasan A. R., et al. Inherently safer sustained casing pressure testing for well integrity evaluation, Journal of Loss Prevention in the Process Industries, 29(2014) 209215, DOI:10.1016/j.jlp.2014.02.012.

[6] Yan W., Zou L., Li H., et al. Investigation of Casing Deformation during Hydraulic Fracturing in High Geo-stress Shale Gas Play, Journal of Petroleum Science and Engineering, 150(2016) 22-29, DOI: 10.1016/j.petrol.2016.11.007.

[7] Lin T., Yu H., Lian Z., et al. Numerical simulation of the influence of stimulated reservoir volume on in-situ stress field, Journal of Natural Gas Science and Engineering, 36(2016) 1228-1238, DOI: 10.1016/j.jngse.2016.03.040.

[8] Zhang, W., Eckert, A., Liu, X. Numerical Simulation of Micro-Annuli Generation by Thermal Cycling. 51st U.S. Rock Mechanics/Geomechanics Symposium, American Rock Mechanics Association. San Francisco, 2017. ID: ARMA-20170354.

[9] B. Nagy, International Conference on Computational and Experimental Science and Engineering (ICCESEN 2014), 25-29 October, 2014 Antalya-Turkey. DOI: 10.12693/APhysPolA.128.B314.

[10] M. Koru and O. Serçe. Experimental and Numerical Determination of Casting-Mold Interfacial Heat Transfer Coefficient in the High Pressure Die Casting of A-360 Aluminum Alloy 130(2016) 453458. DOI: 10.12693/APhysPolA.130.453.

[11] F. Kulal1, I. Akkurt, N. Özgür, International Conference on Computational and Experimental Science and Engineering (ICCESEN 2015), 14-19 October, 2015 Antalya-Turkey. DOI: 10.12693/APhysPolA.130.496.

[12] O. Ipek, M. Kan, B. Gurel, International Conference on Computational and Experimental Science and Engineering (ICCESEN 2015), 14-19 October, 2015 Antalya-Turkey.

DOI: 10.12693/APhysPolA.132.580.

[13] Gao C, Xie L Z, Xie H P, et al. 2017. Estimation of the equivalent elastic modulus in shale formation: Theoretical model and experiment[J]. Journal of Petroleum Science and Engineering, 151:468-479. DOI: 10.1016/j.petrol.2016.12.002. 